Article

\title{
Acoustic Roughness Measurement of Railhead Surface Using an Optimal Sensor Batch Algorithm
}

\author{
Wootae Jeong ${ }^{1,2} * \mathbb{D}$ and Dahae Jeong 2 (i) \\ 1 Transportation Environmental Research, Korea Railroad Research Institute, Uiwang 16105, Korea \\ 2 Dept. of Robotics and Virtual Engineering, University of Science \& Technology, Daejeon 34113, Korea; \\ dahaejeong1@gmail.com \\ * Correspondence: wjeong@krri.re.kr; Tel.: +82-31-460-5817
}

Received: 17 February 2020; Accepted: 17 March 2020; Published: 20 March 2020

Featured Application: Results and algorithm proposed in this research can be applicable in developing devices measruing acoustic rail surface irregularities, and various potental surface measuring equipment with a moving platform.

\begin{abstract}
Contact and friction between wheel and rail during train operation is the main cause of the rolling noise for which railways are known. Therefore, it is necessary to accurately measure the surface roughness of wheels and rails to monitor railway noise and predict noise around tracks. Conventional systems developed to measure surface roughness have large deviations in measured values or low repeatability. The recently developed automatic mobile measurement platform known as Auto Rail Checker (ARCer) uses three displacement sensors to reduce measurement deviation and increase the accuracy of existing systems. This paper proposes enhancing the chord offset synchronization algorithm applied to the existing ARCer for high measurement precision with only two displacement sensors. As a result, when the two sensor-based measurement algorithm was applied, the spectrum level at $\lambda=0.314 \mathrm{~m}$, the wavelength amplification associated with wheel diameter, was reduced to at least $6 \mathrm{~dB}$ in comparison with that of the three sensors based algorithm. We also verified the accuracy of the proposed batch algorithm through a field test on an operating rail track with a corrugated rail surface.
\end{abstract}

Keywords: acoustic roughness; rolling noise; rail surface measurement; optimal sensor batch; chord offset measurement method

\section{Introduction}

The noise and vibration from train operations create noise pollution for residents living near rail tracks, gradually deforms rail track structures, and increase maintenance costs. Therefore, accurate measurement of railway noise provides the essential data needed to analyze and predict such noise and helps to monitor and preventively manage track conditions.

Railway noise can be classified into traction, rolling, and aerodynamic noise. While aerodynamic noise is generated by friction of the front head, body, pantograph, and space between cars with air during high-speed operation, traction noise is caused by a power source such as an engine, traction motor, colling fans, and equipment installed under the car body [1]. Rolling noise is generated by unevenness of the wheel/rail running surface. Rolling noise is also the most important source of noise at the speed domain of $30-250 \mathrm{~km} / \mathrm{h}$, which is the typical operating speed of urban train [2]. Relatively, the impact of traction noise is greatest at low speeds while the impact of aerodynamic noise becoming greatest at higher speeds. As shown in the TWINS model [3,4] in Figure 1, rolling noise is based on the theory that irregularities of the wheel and rail running surfaces cause the wheel and rail to vibrate 
relative to one another; these vibrations are transmitted through the structures and thereby, radiate noise [4-7]. As such, measuring, analyzing, and predicting rolling noise caused by contact surface irregularity is critical to managing railway noise related to train operations [8,9]. In this, the accurate measurement system is critical and also main focus of this paper.

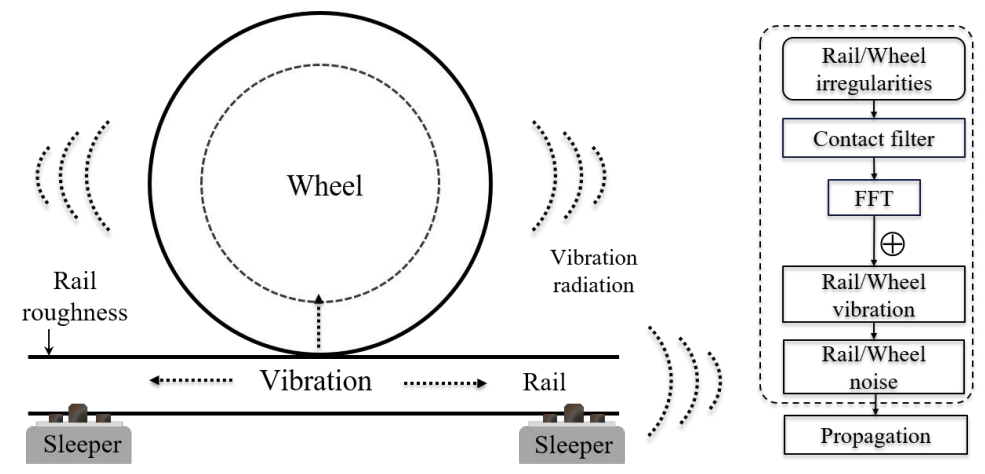

Figure 1. Generation of rolling noise with the TWINS model.

The surface irregularities ("roughness") of a railway track can be expressed as a function of wavelength, with each wavelength related to the frequency generated by the noise according to speed. Irregularities with a wavelength $\lambda$ (in $\mathrm{m}$ ) produce excitation at a frequency $f=V / \lambda$, where $\mathrm{V}$ is the train speed in $\mathrm{m} / \mathrm{s}$. Therefore, for a frequency range $100-5000 \mathrm{~Hz}$, and normal train speeds (50-160 km/h), roughness with wavelengths approximately 3-450 mm needs to be measured [3].

The wavelength of acoustic roughness related to rolling noise increases with the speed of the train on the rail. A rail surface with a long wavelength generates dynamic stress and causes structure-born noise $(0 \mathrm{~Hz}-100 \mathrm{~Hz})$, while the relatively short wavelength on the rail surface, defined by rail surface irregularity or acoustic roughness of the rail is the main cause of air-born noise $(30 \mathrm{~Hz}-5 \mathrm{kHz})$ transmitted from a high-frequency domain to the air [10]. The purpose of this paper was to measure acoustic roughness amplitude $(0.1-100 \mu \mathrm{m})$ at the frequency band of $500-2000 \mathrm{~Hz}$ for general urban train operational speeds (50-120 km/h) and their wavelength of 7-70 mm. International standards specify the wavelength ranges used in measurement of acoustic roughness and prediction of rolling noise to be 3.15-630 mm (EN ISO 3095) [11], 3.15-250 mm (EN 15610) [12], and 10-1000 mm (EN 13231-3) [13].

Various mobile measurement systems are available to measure acoustic roughness and analyze rolling noise. Measurement of rail surface roughness uses an acceleration sensor installed on a mobile platform [14] or displacement sensor fixed on a platform, which is generally mounted on a trolley-type mobile measurement system [15]. Other methods include a fixed system installed on a rail to move non-contact sensors, such as a laser displacement sensor. The recently developed method using a displacement sensor in contact with rail surface measures relative displacement from upper platform to rail surface to observe displacement fluctuations caused by surface unevenness when the measurement system platform moves while maintaining a specific height from the surface and converting those fluctuations into rail surface roughness. However, such a moving platform results in inaccurate amplitude and phase of the measured values since the reference position for measurement is not fixed and the sensor can be inclined. Therefore, new ways like the chord offset synchronizing method, which assumes that the rail surface is a sinusoidal wave consisting of various wavelengths and uses multiple sensors so that each one compensates for the measured values of the others, have been proposed and used to make up for the structural shortcomings of mobile measuring systems equipped with displacement sensors [16,17].

This paper proposes reducing deviation and increasing precision in measuring acoustic roughness of rail surfaces with only two sensors, thereby improving the three-sensor chord offset synchronizing method. In particular, only with two sensor-based algrorithms, we have verified that the proposed algorthm can sucessfully reduce the overamplication problem of specific wavelengh which is related 
to the eccentricity of wheel center in the mobile platform. The proposed algorithm was also validated through a field test of railway operation track.

\section{Measurement of Rail Acoustic Roughness and Method}

The methods of longitudinal measurement of rail surface roughness using a mobile trolley-type device include indirect calculation of displacement between the platform and the rail surface by double integration using an acceleration sensor and direct calculation of surface displacement using a displacement sensor $[14,15,18]$. Although accelerometer-based measuring systems using an acceleration sensor do not require reference data to measure rail surface and can thus be easily applied to a mobile measurement platform, they are sensitive to vibration of the measurement system itself and thus, additional means are needed for dynamic isolation of the acceleration sensor and the fixed platform [19]. The resulting values are also very sensitive to measurement speed during manual measurement. Moreover, using double integration to calculate displacement value from measured acceleration value is the main cause of reduced accuracy and numerical error [20]. Therefore, mobile measuring systems using displacement sensors have recently seen wider use.

\subsection{Chord Offset-Based Measurement}

Although a measurement system using a displacement sensor can directly measure the displacement of a rail surface, the measured value differs from actual rail surface roughness since the sensor only measures the relative displacement while fixed on a moving platform. The system compensates for these errors by assuming the rail surface is a sinusoidal wave with amplitude $Y$ and wavelength $\lambda(y(x)=Y \sin (k x)=Y \sin (2 \pi x / \lambda))$, defining the ratio of the length of the measurement system (chord length, $\mathrm{L}$ ) to the sensor position, and calculating the transfer function of rail roughness and the measured value [21]. However, specific wavelengths of rail surface can be unmeasureable or overamplified depending on the position of sensor on the platform. When considering that rolling noise has an important wavelength $\lambda=5 \sim 250 \mathrm{~mm}$, an analytical method reflecting the measurement wavelength range is needed for accurate analysis of rail acoustic roughness.

Therefore, the multi-sensor chord offset method, using the compensating method with multiple sensor's measurement, has been used in the analysis of acoustic rail roughness to get around being confined to measuring a specific wavelength range in a compact mobile measurement system [22]. While the conventional chord offset method is able to analyze measured values in the sinusoidal form, it has a limited correctable wavelength domain and lower measurement accuracy if there are irregular spikes or pits on the rail surface. Additionally, the multi-sensor chord offset method requires at least three sensors to measure the acoustic roughness of the rail surface correctly.

A sliding surface contact method may be used for the platform instead of a drive wheel to reduce data distortion caused by movement of the mobile measurement system platform [23], but it is difficult to automate, and the measured value may vary greatly by user. Moreover, this increases the platform size rendering it more difficult to manufacture. The recently proposed chord offset synchronizing method has the design of a mobile measurement system that uses at least three sensors to increase data accuracy and reduce external disturbances from the driving wheel at the same time by mutually compensating for the amplitude and phase of the measurement value [17]. This paper proposes to increase the accuracy and reliability of acoustic roughness measurement through mutual compensation using only two displacement sensors in the mobile rail surface measurement system.

\subsection{Chord Offset Synchronizing}

As depicted in Figure 2, the chord offset synchronizing method assumes that the measurement system, whose chord length is $\mathrm{L}$ and sensor position is $\mathrm{d}$, moves on the rail in sinusoidal form 
$(y(x)=Y \sin (k x)=Y \sin (2 \pi x / \lambda))$ and has a random wavelength. Equations (1) and (2) show the coordinates of two wheels in contact with the rail.

$$
\begin{aligned}
& y_{r}=Y \sin \left(k x_{r}\right) \\
& y_{f}=Y \sin \left(k x_{f}\right)
\end{aligned}
$$

Here, $\mathrm{Y}$ is the amplitude of the sinusoidal rail, while $\mathrm{k}$ is $2 \pi / \lambda$. Based on the Equations (1) and (2), and the structure of Figure 2, the sensor position on the rail (P in Figure 2) and the sensor position on the platform ( $\mathrm{Q}$ in Figure 2) can be calcuated as shown below.

$$
\begin{gathered}
P=y\left((1-\alpha) x_{r}+\alpha x_{f}\right) \\
Q=(1-\alpha) y\left(x_{r}\right)+\alpha y\left(x_{f}\right)
\end{gathered}
$$

where $\alpha=d / L=d^{\prime} /\left(x_{f}-x_{r}\right), d^{\prime}$ is the projecton of $d$ to the $x$-axis, $\mathrm{P}$ and $\mathrm{Q}$ are $y$-axis coordinate of the sensor position on rail and platform respectively. Since the actual value $z(x)$ measured by the sensor is the actual distance between the sensor position on the platform and the vertical rail waveform, it can be expressed as follows:

$$
\begin{aligned}
z(x) & =P-Q \\
& =y\left((1-\alpha) x_{r}+\alpha x_{f}\right)-\left\{(1-\alpha) y\left(x_{r}\right)+\alpha y\left(x_{f}\right)\right\} \\
& =Y \sin \left(k(1-\alpha) x_{r}+\alpha k x_{r}\right)-(1-\alpha) Y \sin \left(k x_{r}\right)-\alpha Y \sin \left(k x_{f}\right)
\end{aligned}
$$

where $y(x)=Y \sin (k x)$ from the Equations (1) and (2).

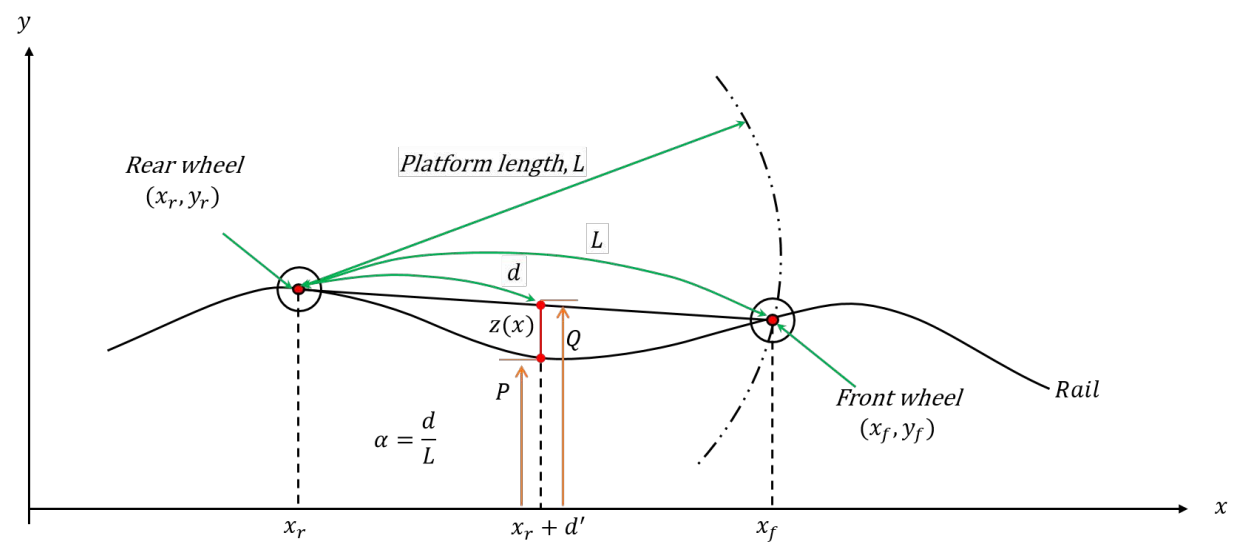

Figure 2. Single-sensor-based chord offset synchronizing model ( $d$ is the distance between $x_{r}$ and the sensor, and $d^{\prime}$ is the projection of $d$ ) (Adapted and modified from [17]).

Therefore, amplitude $(Z=|z(x)|)$ and phase $(\Phi=$ phase $(z(x)))$ can be obtained from the sensor measurement and the transfer function of the measured value for the rail surface roughness can be defined as follows:

$$
H(\lambda)=Z(\lambda) / Y(\lambda)
$$

The transfer function in Equation (6) can calculate the relative amplitude and phase angle of the measured rail surface value and can predict amplification of the measured sensor value and the change in phase angle according to sensor position. When measuring rail surface roughness using a sensor, the measured value can differ from actual value due to amplification or attenuation according to wavelength $(\lambda)$, equipment length $(L)$, and sensor position (d) even when analyzing the measured value by reflecting platform inclination. Moreover, it is difficult to compensate for the built-in measurement 
error of the conventional trolley-type mobile measurement system. Therefore, the recently proposed chord offset synchronization method uses multiple sensors with consideration given to actual platform length (L) and measured wavelength range, mutually compensating for amplification or attenuation to reduce measured value errors [17]. This has the advantage of a compensated value that differs according to relative distance between the sensors, more accurate measurement than the existing analysis method throughout the various wavelength ranges on the rail surface when using optimal sensor layout, and analysis of rail cracks or irregularities. However, to increase measurement accuracy, the method requires at least three sensors in various positions to be synchronized to the measurement from the same position.

Figure 3 shows the multi-sensor-based chord offset synchronizing model that calculates the measurement value and phase difference using two or more sensors. Calculating batch positions for three sensors on the platform with wheelbase $(\mathrm{L}=716 \mathrm{~mm})$ and wheel diameter $(\mathrm{D}=100 \mathrm{~mm})$ using this model results in $d_{1}=222 \mathrm{~mm}, d_{2}=327 \mathrm{~mm}$, and $d_{3}=432 \mathrm{~mm}$. Here, di is the distance between the rear wheel and the $i^{\text {th }}$ sensor [17].

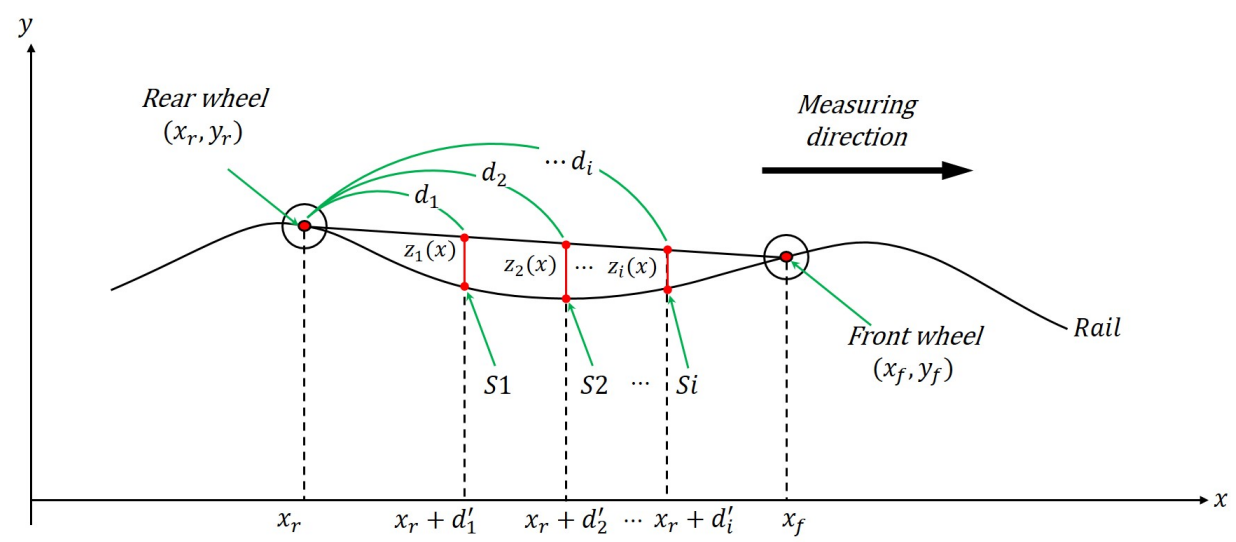

Figure 3. Multi-sensor-based chord offset synchronizing model $\left(\alpha_{i}=d_{i} / L\right.$, and $d_{i}$ is the distance from $x_{r}$ to the $i^{\text {th }}$ sensor $(i=1,2,3)$ ) (Adapted and modified from [17]).

\subsection{Chord Offset Synchronizing with Two Sensors}

Although using multiple sensors can increase measured value accuracy and minimize the impact of external disturbances on the platform wheel, as shown in the spectrum analysis of rail surface roughness (see Figures 10 and 12 at later field test), at least three sensors are needed on the platform. Therefore, we sought the same accuracy of three sensors even when using two sensors on a platform in the case that the wavelength range to be measured has a limitation.

First, it was assumed the wheelbase between the front and rear wheels of the platform to be $716 \mathrm{~mm}$ and specified the wavelength related to rolling noise of the rail surface to be $5-500 \mathrm{~mm}$. The following equation is obtained when calculating the transfer function of the sensor measurement to the rail surface roughness value $H(\lambda)=Z(\lambda) / Y(\lambda)$ for each sensor position change and calculating the sum of squared residuals (SSR) using the residual, $r=H(\lambda)-\widehat{H(\lambda)}$, when the amplification ratio is 1 .

$$
S S R=\sum_{i=1}^{n} r_{i}^{2}=\sum_{i=1}^{n}\left(H_{i}(\lambda)-\widehat{H_{i}(\lambda)}\right)^{2}=\sum_{i=1}^{n}\left(H_{i}(\lambda)-1\right)^{2}
$$

where $H_{i}(\lambda)$ is the observed response value at the $i^{t h}$ measured point and $\widehat{H_{i}(\lambda)}$ is the fitted response value at the $i^{\text {th }}$ measurement. The fitted response becomes one when input and output is coincident. To minimize amplification ratio of the measured value, we can calculate the sensor position that minimizes SSR obtained above. Figure 4 shows the results of SSR calculation by changing the sensor position for two sensors $\left(S_{1}\right.$ and $\left.S_{2}\right)$ on the above platform. The results show that the positions of the 
two sensors with minimum SSR at the critical wavelength range $(5-500 \mathrm{~mm})$ where the rolling noise occurs are $d_{1}=255 \mathrm{~mm}$ and $d_{2}=380 \mathrm{~mm}$ from the rear wheel.

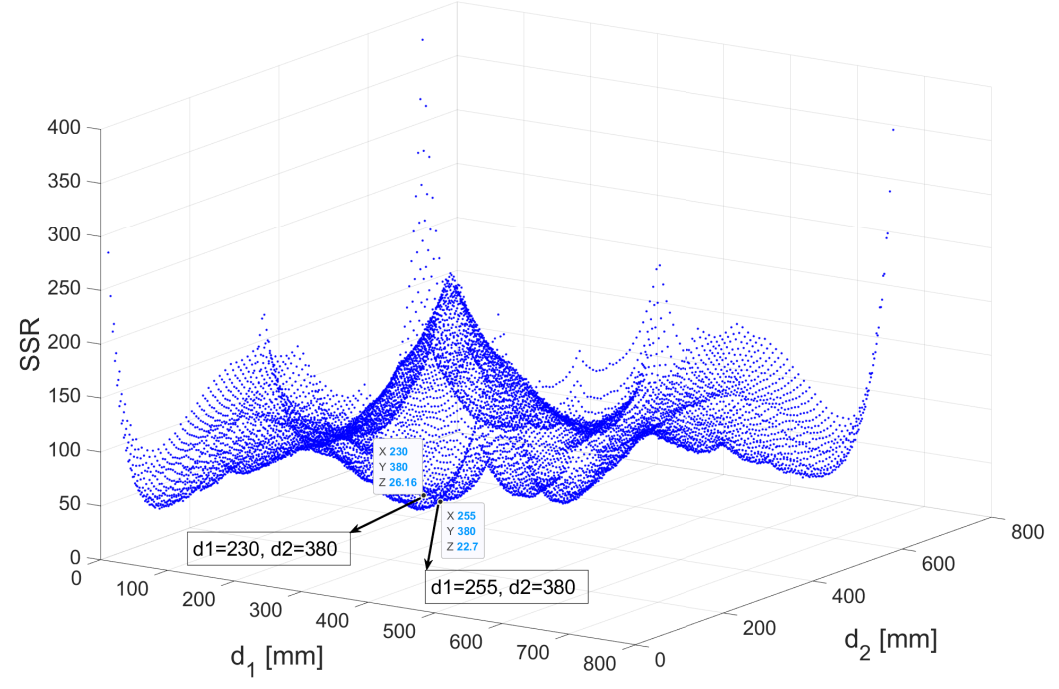

Figure 4. Results of SSR as the location of two sensors changes(Minimum SSR at $d_{1}=255 \mathrm{~mm}$ and $d_{2}=380 \mathrm{~mm}$ ).

Figure 5 shows a comparison of the transfer function values of the chord offset synchronization method using three sensors and that of the two sensors with the minimum SSR. As shown in the graph, the total SSR with the two sensors has much less value at the $300 \mathrm{~mm}$ or higher wavelength band which is the main interest, although the SSR values of the transfer function at lower wavelength are irregular.

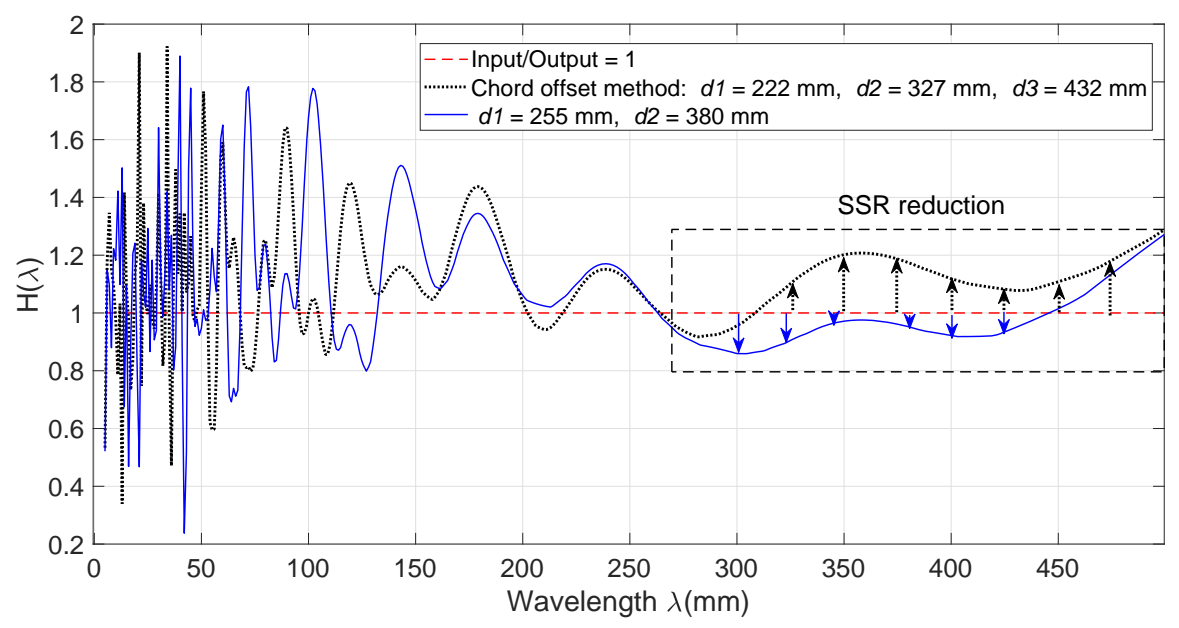

Figure 5. Minimized residual results with two sensors using the chord offset synchronization.

However, applying the optimized two sensor positions to the measurement platform with the drive wheel (wheel diameter of $100 \mathrm{~mm}$ ) can affect the measured value significantly in the frequency distortion $(\lambda=2 \pi R=314 \mathrm{~mm})$ associated with drive wheel eccentricity. Therefore, we determined the sensors whose residual calculation in $\lambda=314 \mathrm{~mm}$ converged to 0 first and then calculated the final positions to minimize the SSR in the wavelength range of the total rolling noise. The calculated positions of the two sensors are $d_{1}=230 \mathrm{~mm}$ and $d_{2}=380 \mathrm{~mm}$, and the SSR value, in that case, is 26.16 . Figure 6 shows a comparison of these results with the transfer functions values of the existing sensor positions. Since the amplitude of the transfer function using recalculated two sensors approaches to 1 
as shown in the red line of Figure 6, the overamplified spectrum respond at a wavelength of $314 \mathrm{~mm}$ can be reduced in comparison with that of two sensors with a minimum SSR. These analytical results will be verified through field experiment.

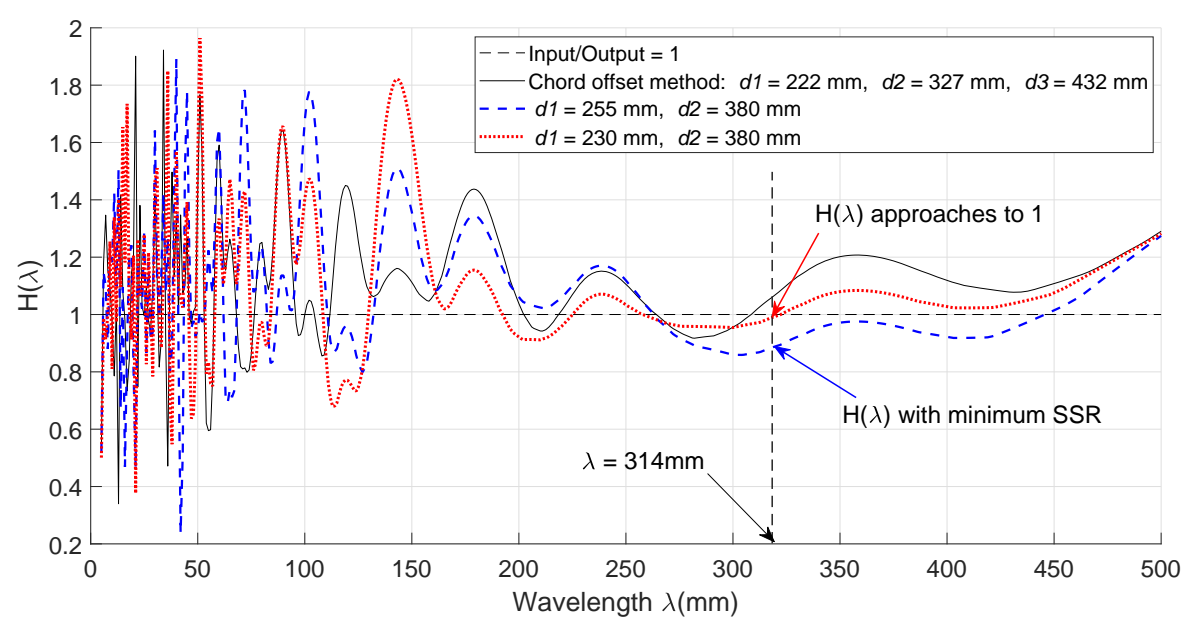

Figure 6. Minimized residual results with two sensors focused on a periodic wavelength in the chord offset synchronization method.

\section{Field Test and Results}

We conducted a measurement test of a field track using the calculated optimal sensor positions to verify the results. The test measured acoustic roughness of the operating rail track surface using constant speed control with the ARCer [24] shown in Figure 7. The new ARCer featured a real-time operating system, speed controller, rotary encoder to measure distance, and wireless data communication. ARCer had a wheelbase of $716 \mathrm{~mm}$, front and rear drive wheels $100 \mathrm{~mm}$ in diameter, a maximum driving speed of $4 \mathrm{~m} / \mathrm{s}$, a measurement speed of $0.5 \mathrm{~m} / \mathrm{s}$, and the capability for up to three sensors in adjustable positions (see Figure 7). Measurement and analysis of the longitudinal rail surface roughness conformed to the standard presented in EN 15610:2019 [12].

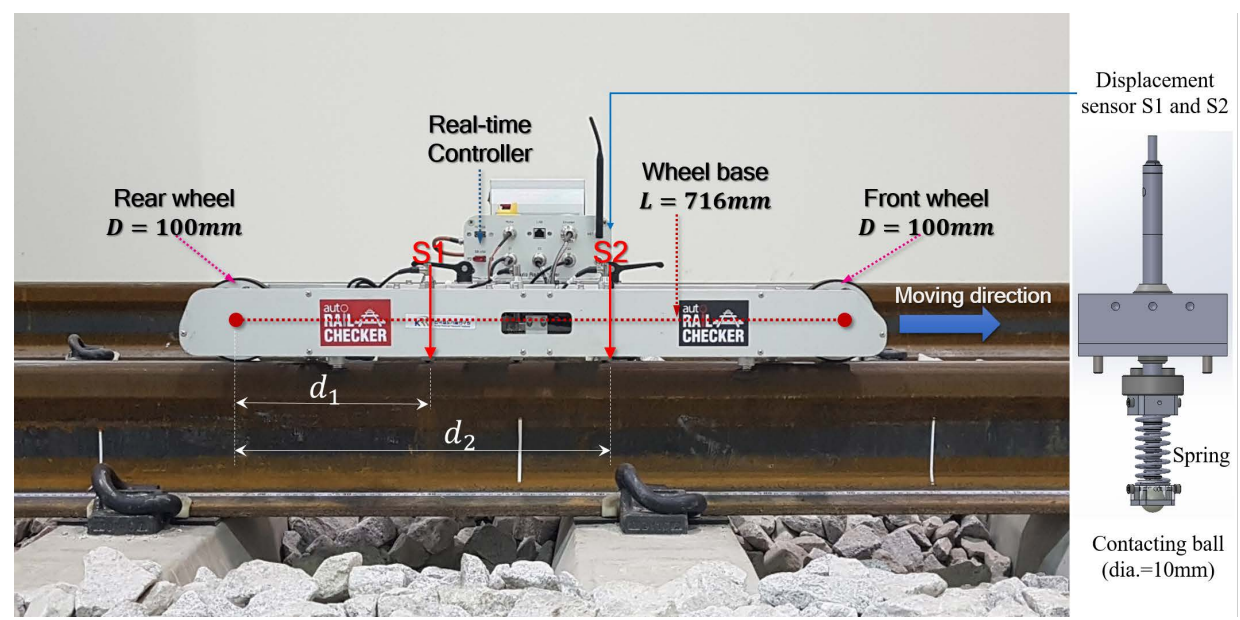

Figure 7. Auto Rail Checker (ARCer) with two displacement sensors and the detailed structure of the sensor; S1 and S2 are the position of the first and second sensor (Adapted and modified from [17]).

The first field test was conducted on a track inside tunnel " $Y$ " that had abrasion wear and corrugation in some track sections (see Figure 8). We measured every $10 \mathrm{~m}$ of two sections of the track in the tunnel using ARCer. The first section $\mathrm{A}$ as shown in Figure $8 \mathrm{~b}$ has a corrugated railhead surface of $65 \mathrm{~mm}$ wavelengh. The first section A as shown in Figure 8c has a normal worn railhead surface. 
The positions of the sensors attached to the measurement system were $d_{1}=222 \mathrm{~mm}, d_{2}=327 \mathrm{~mm}$, and $d_{3}=432 \mathrm{~mm}$ for three sensors and $d_{1}=255 \mathrm{~mm}$ and $d_{2}=380 \mathrm{~mm}$ for two sensors. The positions of the two sensors did not mitigate the wavelength level at $\lambda=0.314 \mathrm{~m}$ associated with wheel diameter of the measurement system.

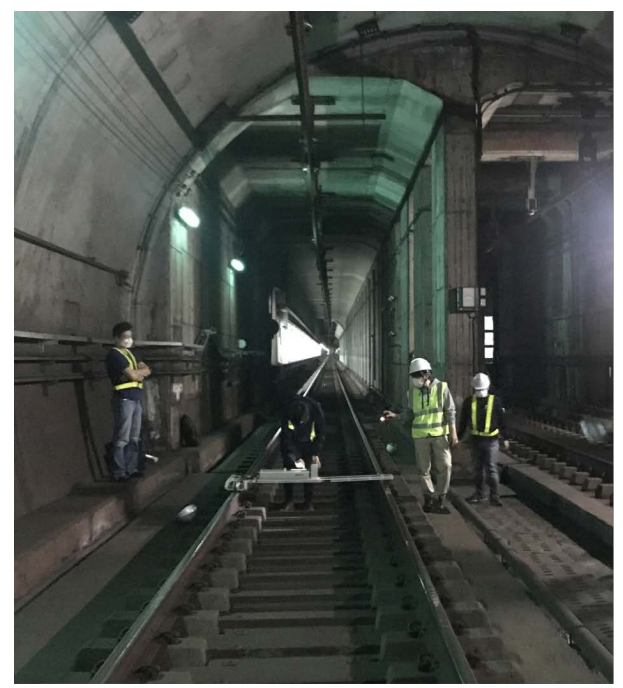

(a) Tunnel track "Y" for field experiment

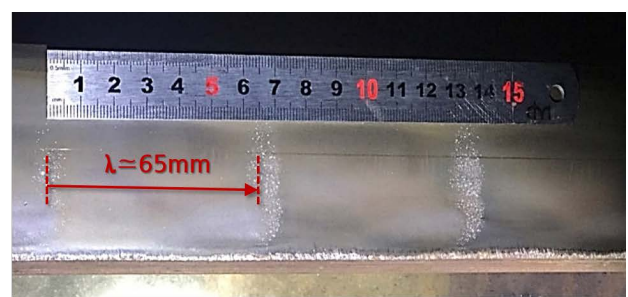

(b) Corrugated rail section A in field track "Y"

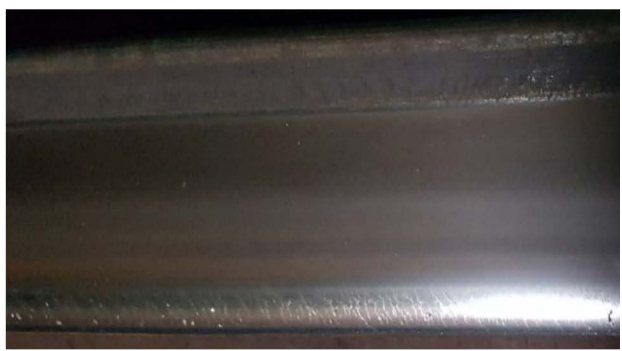

(c) Worn rail section B in field track "Y"

Figure 8. Railway track field experiment; (a) Tunnel track "Y", (b) Corrugated rail section A, (c) Normal rail section $B$.

Figures 9 show the logitudinal rail surface roughness of the track " $Y$ " for the two track sections, which are illustrated in Figure $8 \mathrm{~b}, \mathrm{c}$. The section A shows larger deviation in measured roughness because of the developed corrugation. Figure 10 shows the spectrum of acoustic roughness of the rail surface obtained through the acoustic roughness values measured by the two and three sensors and the frequency analysis. While there is high peak at the corrugated wavelength of $0.065 \mathrm{~m}$ in Figure 10a, there is no peak at the smooth railhead surface in Figure 10b except the wheel diameter related wavelength of $0.314 \mathrm{~m}$. Although the field measurements of the two track sections match in most rolling noise wavelengths, the acoustic roughness value showed a gap of more than $6 \mathrm{~dB}$ at the wavelength $\lambda=0.314 \mathrm{~m}$ associated with wheel diameter. To compensate for the measurement error at this wavelength, we used new sensor positions to verify the results.

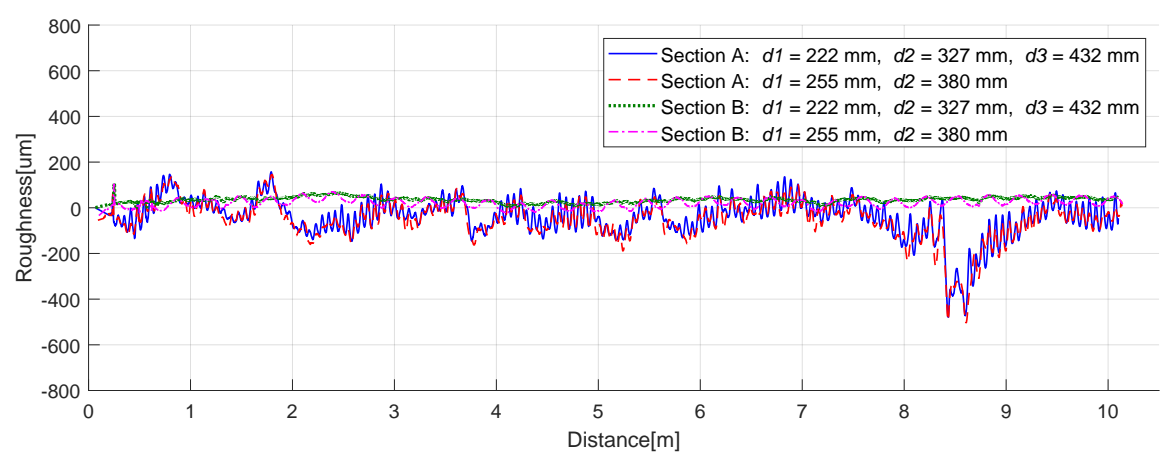

Figure 9. Rail surface roughness of track sections in tunnel "Y". 


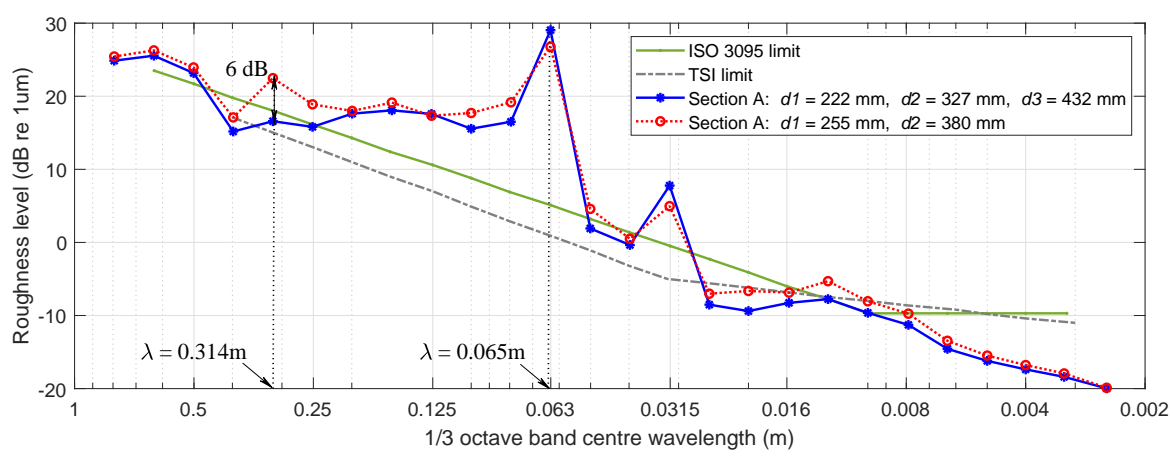

(a)

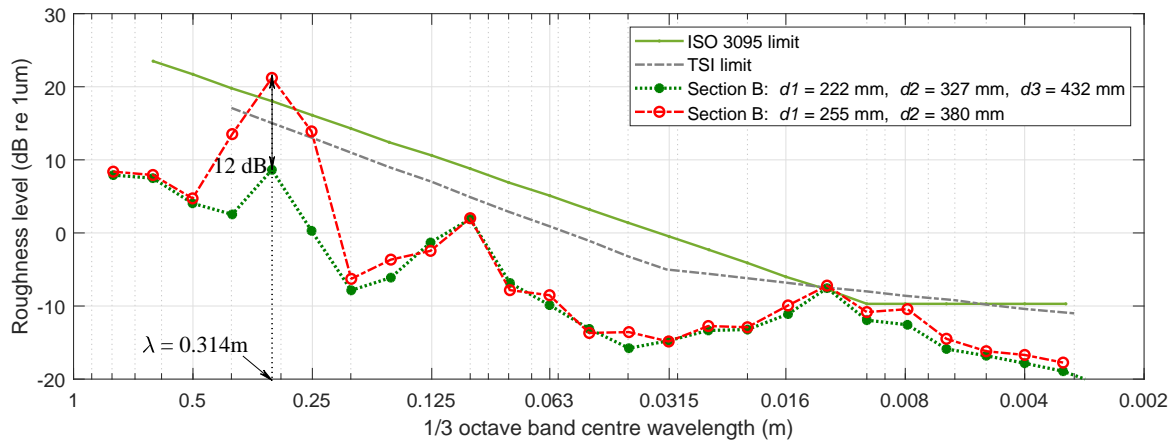

(b)

Figure 10. Spectral analysis of railhead roughness in tunnel "Y" track; (a) Corrugated rail section A, (b) Normal worn rail section B.

We also conducted a field test on the second track (" $Z$ " track), which had no abrasion wear or corrugation, to directly check the measured value of the wheel and verify the measurement results of the proposed optimal two sensors. The test used the same two- and three-sensor positions as in the previous test and used an additional two optimum sensor positions $\left(d_{1}=230 \mathrm{~mm}\right.$ and $\left.d_{2}=380 \mathrm{~mm}\right)$ to compare. Figure 11 shows the measured section and rail, while Figure 12 shows the results of the spectrum analysis of acoustic roughness using three different algorithms. As shown in Figure 12, when the optimization algorithm is used, the spectrum level at $\lambda=0.314 \mathrm{~m}$, the wavelength associated with wheel diameter, converged in the same way as the three sensor-based algorithm.

The results of the field tests of these two sections verified that the proposed batch algorithm using two sensors could generate the same level of measurement accuracy as using three sensors.
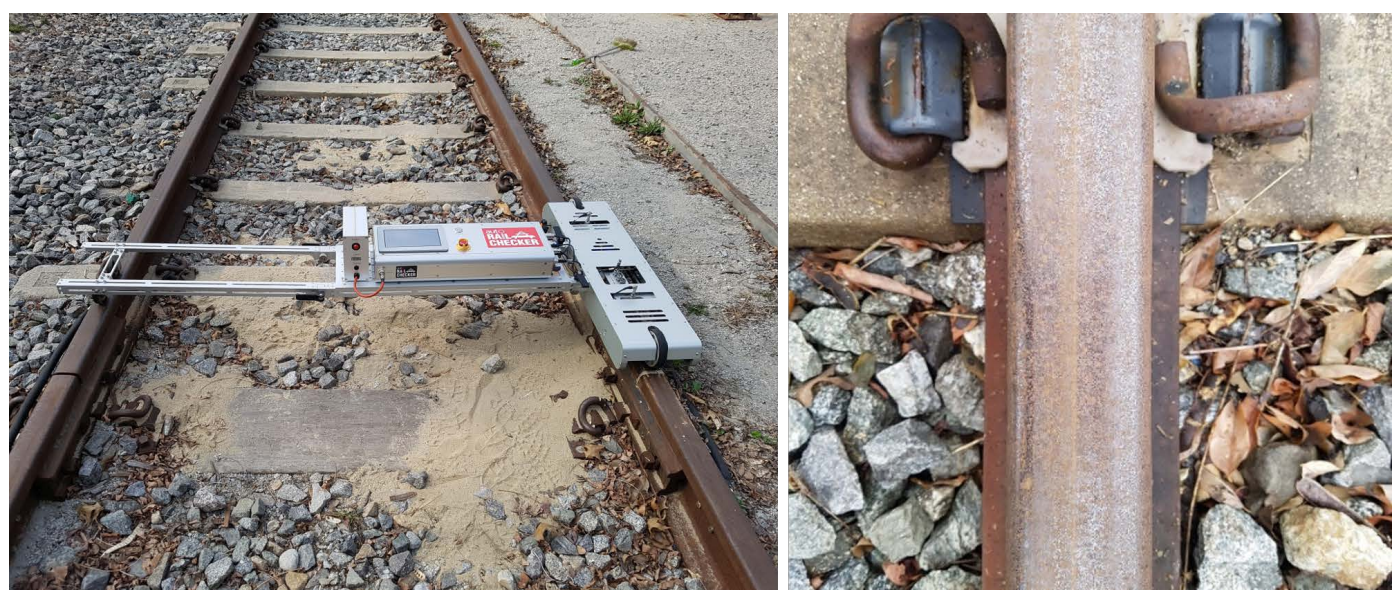

Figure 11. Field experiment on " $Z$ " track. 


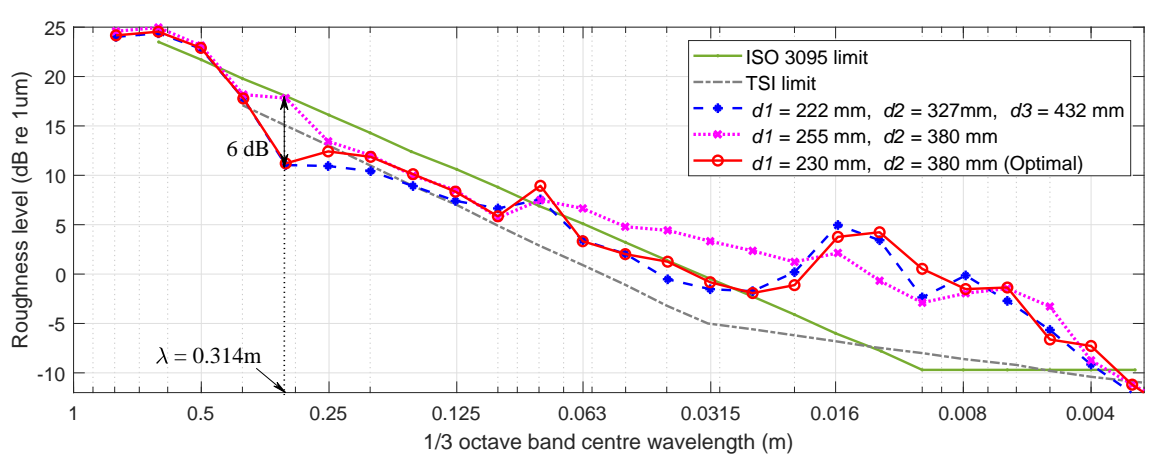

Figure 12. Spectral analysis of measured roughness on the field track " $\mathrm{Z}$ ".

\section{Conclusions}

The ARCer system, developed to automatically measure rail surface acoustic roughness, optimizes the positions of three sensors to measure accurate rail surface and spectrum level. This paper proposes using a minimized number of sensors (two) and improving the measurement platform to show the same level of measurement accuracy. The new method optimizes a calculation algorithm to reduce measurement errors in the specific wavelength range generated by the drive wheel with fewer sensors. To compare the new method's performance with the existing measurement system using three sensors, we conducted two field tests to verify measurement results. As a result, we compensated for acoustic roughness in the wavelength range associated with drive wheel diameter generated when using two sensors for optimization. More specifically, the spectrum level at $\lambda=0.314 \mathrm{~m}$ was reduced to at least $6 \mathrm{~dB}$ in comparison with that of the three sensors based algorithm. Using ARCer with two sensors to measure rail acoustic roughness is more user-friendly and reduces mannufacturing cost and the burden of data transfer over existing systems and thus is expected to be more useful in automated measurement systems.

Author Contributions: Data curation, D.J.; formal analysis, W.J. and D.J.; investigation and supervision, W.J.; methodology, W.J. and D.J.; writing and editing, W.J. All authors have read and agreed to the published version of the manuscript.

Funding: This research was supported by a grant from the R\&D program of the Korea Railroad Research Institute, Republic of Korea.

Conflicts of Interest: The authors declare no conflict of interest.

\section{References}

1. Thompson, D. Railway Noise and Vibration: Mechanisms, Modelling and Means of Control; Elsevier: Amsterdam, The Netherlands, 2009.

2. Hemsworth, B. Environmental Noise Directive Development of Action Plans for Railways. UIC. 2008. Available online: https:/ / uic.org/IMG/pdf/action_planning_paper_final-2.pdf (accessed on 6 March 2020).

3. Thompson, D.; Hemsworth, B.; Vincent, N. Experimental validation of the TWINS prediction program for rolling noise, Part 1: Description of the model and method. J. Sound Vib. 1996, 193, 123-135. [CrossRef]

4. Thompson, D.; Fodiman, P.; Mahe, H. Experimental validation of the TWINS prediction program for rolling noise, Part 2: Results. J. Sound Vib. 1996, 193, 137-147. [CrossRef]

5. Thompson, D.; Jones, C. A review of the modelling of wheel/rail noise generation. J. Sound Vib. 2000, 231, 519-536. [CrossRef]

6. Thompson, D. On the relationship between wheel and rail surface roughness and rolling noise. J. Sound Vib. 1996, 193, 149-160. [CrossRef]

7. Grassie, S.L.; Kalousek, J. Rail corrugation: Characteristics, causes and treatments. J. Sound Vib. 1993, 207, 57-68. [CrossRef]

8. Remington, P.J. Wheel/rail noise, Part IV:rolling noise. J. Sound Vib. 1976, 46, 419-436. [CrossRef]

9. Remington, P.J. Wheel/rail rolling noise, I:theoretical analysis. J. Sound Vib. 1987, 81, 1805-1823. 
10. Han, J.; Xiao, X.; Wu, Y.; Wen, Z.; Zhao, G. Effect of rail corrugation on metro interior noise and its control. Appl. Acoust. 2018, 130, 63-70. [CrossRef]

11. ISO 3095: 2013 Acoustics-Railway Applications-Measurement of Noise Emitted by Railbound Vehicles. Available online: https:/ / www.iso.org/standard/55726.html (accessed on 13 February 2020).

12. BS EN 15610:2019 Railway Applications. Acoustics. Rail and Wheel Roughness Measurement Related to Noise Generation. Available online: https:/ / shop.bsigroup.com/ProductDetail/?pid=000000000030304302 (accessed on 13 February 2020).

13. BS EN 13231-3:2012 Railway Applications-Track-Acceptance of Works, Part 3; Acceptance of Reprofiling Rails in Track. Available online: https://shop.bsigroup.com/ProductDetail/?pid=000000000030209366 (accessed on 13 February 2020).

14. Grassie, S.L. Rail corrugation: Advances in measurement, understanding and treatment. Wear 2005, 258, 1224-1234. [CrossRef]

15. Verheijen, E. A survey on roughness measurements. J. Sound Vib. 2006, 293, 784-794. [CrossRef]

16. Jeong, W.; Jeon, S.; Jeong, D.; Choi, H. Effect of design variables of rail surface measuring device on acoustic roughness and spectral analysis. J. Korean Soc. Railw. 2017, 20, 440-447. [CrossRef]

17. Jeong, D.; Choi, H.S.; Choi, Y.J.; Jeong, W. Measuring acoustic roughness of a longitudinal railhead profile using a multi-sensor integration technique. Sensors 2019, 19, 1610. [CrossRef] [PubMed]

18. Dong, C.; Mao, Q.; Ren, X.; Kou, D.; Qin, J.; Hu, W. Algorithms and instrument for rapid Detection of rail Surface defects and vertical short-wave irregularities based on FOG and odometer. IEEE Access 2019, 7, 31558-31572. [CrossRef]

19. Zilong, W.; Núñez, A.; Li, Z.; Dollevoet, R. Evaluating degradation at railway crossings using axle box acceleration measurements. Sensors 2017, 17, 2236. [CrossRef] [PubMed]

20. Thong, Y.K.; Woolfson, M.S.; Crowe, J.A.; Hayes-Gill, B.R.; Jones, D.A. Numerical double integration of acceleration measurements in noise. Measurement 2004, 36, 73-92. [CrossRef]

21. Grassie, S.L. Measurement of railhead longitudinal profiles: A comparison of different techniques. Wear 1996, 191, 245-251. [CrossRef]

22. Tanaka, H.; Shimizu, A. Practical application of portable trolley for the continuous measurement of rail surface roughness for rail corrugation maintenance. Q. Rep. RTRI 2016, 57, 118-124. [CrossRef]

23. Diehl, R.; Holm, P. Roughness measurements have the necessities changed? J. Sound Vib. 2006, 293, 777-783. [CrossRef]

24. Jeong, W.; Jang, S.; Koh, H. Apparatus for Measuring Surface Roughness of Rail Using Acceleration Sensor and Displacement Sensor. Patent European Patent (EP) 3256812, 16 October 2019.

(C) 2020 by the authors. Licensee MDPI, Basel, Switzerland. This article is an open access article distributed under the terms and conditions of the Creative Commons Attribution (CC BY) license (http:/ / creativecommons.org/licenses/by/4.0/). 